\title{
SIGNIFICANT INDUCTION OF EPITHELIAL CELL PROLIFERATION IN THE URINARY BLADDERS OF NCI-BLACK-REITER MALE RATS BY $\boldsymbol{N}$-BUTYL- $\boldsymbol{N}$ - (4-HYDROXYBUTYL) NITROSAMINE
}

\author{
Katsumi Takaba \\ Pathology, Osaka City University Medical School \\ Yoshihiro Nakagawa, Seiichi Ito, and Akira Yoshitake \\ Environmental Health Science Laboratory, Sumitomo Chemical Co. LTD. \\ Hideki Wanibuchi, and Shoji Fukushima \\ First Department of Pathology, Osaka City University Medical School
}

Environmental Health Science Laboratory, Sumitomo Chemical Co. LTD. First Department of

\begin{abstract}
The response of the urinary bladder epithelium in NCI-Black-Reiter (NBR) rats to administration of $N$-butyl- $N$-(4-hydroxybutyl)nitrosamine (BBN), a potent carcinogen in rodents, was examined. Male NBR rats were exposed to 0.05\% BBN in the drinking water for 8 weeks, or no added chemical. Microscopically, simple hyperplasia was observed in the urinary bladder epithelium of treated rats sacrificed at the end of week 4. Moreover, after 8 weeks administration of BBN, papillary or nodular (PN) hyperplasia and squamous metaplasia were produced. Levels of DNA synthesis, as indicated by incorporation of 5-bromo-2'-deoxyuridine, areas of simple and PN hyperplasia in rats treated by BBN were significantly increased than in non-treated ones at the end of week 8 . These results indicate that the urinary bladder of NBR male rats is very responsive to BBN insult. (J Toxicol Pathol 8: 139 143, 1995)

Key words : NCI-Black-Reiter rat, Urinary bladder, Cell proliferation, $\boldsymbol{N}$-butyl- $\boldsymbol{N}$-(4-hydroxybutyl) nitrosamine
\end{abstract}

\section{Introduction}

Species and sex considerably influence the susceptibility to promotion of two-stage urinary bladder carcinogenesis in rodents. For example, sodium L-ascorbate does not exert promoting activity for mouse urinary carcinogenesis, in clear contrast to the case in the rat ${ }^{1}$. Bladder tumor promoting activity of sodium saccharin is greater in male than in female rats ${ }^{2}$ and can not be demonstrated in mice, hamsters, and monkeys ${ }^{3,4}$. The

高場克己 中川善裕 君藤聖一 吉武 彬 锣淵英機 福 島昭治

Accepted for publication : March 2, 1995

Mailing address: Katsumi Takaba, Environmental Health Science Laboratory, Sumitomo Chemical Co. LTD., 3-198, Kasugadenaka, Konohana-ku, Osaka 554, Japan. latter results concerning differences in response to sodium saccharin were recently explained on the basis of $\alpha 2 \mathrm{u}$-globulin, a male rat specific low molecular weight protein that is synthesized in the liver of adult male rats, secreted into the blood and excreted into the urine ${ }^{5}$. Therefore, it is important to investigate the participation of $\alpha 2 \mathrm{u}$-globulin in sodium salt promotion of rat urinary bladder carcinogenesis. NCI-Black-Reiter (NBR) rats were developed in 1966 from heterogeneous stock and the males are known not to synthesize $\alpha 2 \mathrm{u}-$ globulin $^{6,7}$ and therefore of interest for such studies.

N-butyl- $N$-(4-hydroxybutyl)nitrosamine (BBN) is widely used as an initiator for 2-stage rat urinary bladder carcinogenesis protocols ${ }^{1,2,8-13}$. It has been reported that strain differences exist in 
the response of the urinary bladder epithelium to $\mathrm{BBN}^{12,13}$. Since there have been no reports of BBN-treated urinary bladder carcinogenesis in NBR rats, we examined whether the urinary bladder of this strain is susceptible to BBN induction of morphological changes and/or DNA synthesis.

\section{Materials and Methods}

Animals

NBR rats were initially procured from the Laboratory of Animal Resources of the National Cancer Institute, U.S.A. The animals were housed 2-3 rats per cage in stainless-steel wiremesh cages in a controlled environment, maintained on a 12-hour lightdark cycle (light on, $8: 00-20: 00$ ), air-conditioned at $24 \pm 2^{\circ} \mathrm{C}$ and $55 \pm 10 \%$ humidity. Food (CRF-1, Oriental Yeast Co., Tokyo) and water were available ad libitum throughout the experiment.

\section{Experiment}

A total of 12 male NBR rats, 39-weeks-old, were divided into 2 groups, and given drinking water with no additional chemical (control, 3 animals) or containing $0.05 \%$ BBN (Tokyo Kasei Co. LTD., Tokyo ; total 9 animals) for 8 weeks. An interim sacrifice was performed for the BBN treated group ( 4 animals) at the beginning of week 5.

A daily health check was performed. Body weights were checked weekly. Food and water consumptions over 2 days were recorded during weeks 4 and 8.

For urine pH examination, fresh urine samples were obtained from almost all rats by forced urination in the morning at the end of weeks 4 and 8. The urinary $\mathrm{pH}$ was measured with a $\mathrm{pH}$ meter (Twin pH; Horiba, Kyoto). In addition, at the same time points, urine was collected over 24 hours from rats maintained in individual metabolic cages without food. Urine samples were applied for volume measurement and electrolyte analysis, namely of sodium, potassium and chloride with the aid of an automated analyzer (model NEO-5AT, Toa Electronics LTD., Tokyo).

At the end of week 4 and 8 , all rats received a single i.p. injection of 5-bromo-2'-deoxyuridine (BrdU; Sigma Chemical Co., MO, U.S.A.) at a dose of $100 \mathrm{mg} / \mathrm{kg}$ body weight, one hour prior to being killed under either anaesthesia. The urinary bladder was removed from each rat inflated by intraluminal injection of $10 \%$ phosphatebuffered formalin solution, and their immersion fixed in the same fixative. Each bladder was then cut into twelve strips, embedded in paraffin, sectioned routinely, and stained with hematoxylin and eosin.

To achieve immunohistochemical staining of BrdU, sections were reacted with anti-mouse BrdU antibody (DAKO A/S, Denmark) with visualization of binding sites performed using the avidin biotin complex method (Vectastain ABC kit, Vector Laboratories, Inc., CA, U.S.A.). The numbers of cells incorporating $\mathrm{BrdU}$ into the DNA per unit area $\left(\mathrm{mm}^{2}\right)$ and the basement membranous length (mm) of transitional epithelium in the urinary bladder were measured with the help of a color image analyzer (IPAP : Image Processor for Analytical Pathology; Sumika Technos Inc., Hyogo) under the light microscope. Transitional epithelium average heights were calculated as follows: the area of the transitional epithelium divided by the length of basement membrane.

\section{Statistical analysis}

Data for lesion incidences were analysed for statistical significance with the two-tailed chisquare test. Other data were analyzed using the two-tailed Student's $t$ test.

\section{Results}

Clinical observation and values for food and water consumption did not reveal abnormalities or differences between the groups. No deaths occurred during the experimental period.

Urinary analysis data for weeks 4 and 8 are shown in Table 1. Treatment with BBN was not associated with changes of the urinary $\mathrm{pH}$ or volume, or the concentrations of $\mathrm{Na}^{+}$and $\mathrm{K}^{+}$. At week 8 , the urinary chloride level was significantly higher in the BBN-treated group than in the control group. 
Table 1. Data for Urinary Volume, pH, and Electrolytes

\begin{tabular}{|c|c|c|c|c|c|c|}
\hline \multirow{2}{*}{ Treatment } & \multirow{2}{*}{$\begin{array}{c}\text { Effective } \\
\text { No. of rats }\end{array}$} & \multirow{2}{*}{$\mathrm{pH}$} & \multirow{2}{*}{$\begin{array}{l}\text { Volume } \\
\text { (ml/day) }\end{array}$} & \multicolumn{3}{|c|}{ Electrolytes (mEq/l) } \\
\hline & & & & $\mathrm{Na}$ & $\mathbf{K}$ & $\mathrm{Cl}$ \\
\hline \multicolumn{7}{|c|}{ Examination at week 4} \\
\hline Control & 3 & $7.7 \pm 0.5$ & $7.7 \pm 1.5$ & $21.9 \pm 16.7$ & $106.1 \pm 39.8$ & $57.0 \pm 38.5$ \\
\hline BBN treatment & 7 & $8.1 \pm 0.2$ & $8.0 \pm 1.1$ & $40.0 \pm 17.0$ & $114.1 \pm 15.8$ & $75.1 \pm 21.7$ \\
\hline \multicolumn{7}{|c|}{ Examination at week 8} \\
\hline Control & 3 & $8.0 \pm 0.2$ & $7.3 \pm 0.6$ & $9.6 \pm 9.9$ & $81.7 \pm 29.0$ & $34.7 \pm 17.6$ \\
\hline BBN treatment & 5 & $7.7 \pm 0.5$ & $8.3 \pm 1.2$ & $18.3 \pm 9.2$ & $101.1 \pm 9.9$ & $67.4 \pm 8.5^{*}$ \\
\hline
\end{tabular}

BBN = N-butyl-N-(4-hydroxybutyl)nitrosamine

The asterisk indicates a significant difference from the corresponding control value ( $\mathrm{P}<0.05$, Student's $t$ test)

The data given are mean $\pm S D$ values.

Table 2. Histopathological Findings and BrdU Labeling Indices for the Urinary Bladder Epithelium

\begin{tabular}{|c|c|c|c|c|c|c|}
\hline \multirow{2}{*}{ Treatment } & \multirow{2}{*}{$\begin{array}{l}\text { No. of } \\
\text { rats }\end{array}$} & \multicolumn{2}{|c|}{ Hyperplasia } & \multirow{2}{*}{$\begin{array}{l}\text { Squamous } \\
\text { Metaplasia }\end{array}$} & \multirow{2}{*}{$\begin{array}{l}\text { Height of } \\
\text { Epithelium } \\
(\mu \mathrm{m})\end{array}$} & \multirow{2}{*}{$\begin{array}{c}\text { BrdU } \\
\text { Labeling Index } \\
\text { (No./mm² } \\
\text { epithelium) }\end{array}$} \\
\hline & & Simple & PN & & & \\
\hline \multicolumn{7}{|l|}{ Terminal sacrifice } \\
\hline Control & 3 & 0 & 0 & 0 & $9.2 \pm 0.5$ & $7.6 \pm 5.4$ \\
\hline BBN treatment & 5 & $5^{* *}(+*)^{c}$ & $5^{* *}(\#)^{c}$ & $3(+)^{c}$ & $45.3 \pm 7.2^{* * *}$ & $127.6 \pm 15.8^{* * *}$ \\
\hline \multicolumn{7}{|l|}{ Interim sacrificeb } \\
\hline BBN treatment & 4 & $4(\pi)^{c}$ & 0 & 0 & $46.1 \pm 5.7$ & $171.9 \pm 31.3$ \\
\hline
\end{tabular}

BBN = N-butyl-N-(4-hydroxybutyl)nitrosamine

PN = Papillary or nodular

Asterisks indicate significant differences from the corresponding control values $\left({ }^{* *} \mathrm{P}<0.01 ;{ }^{* * *} \mathrm{P}<0.001\right.$, chi square or Student's $t$ test).

acrificed at the end of week 8 .

b Sacrificed at the end of week 4.

c Grading of lesions : + , slight ; \#, moderate ; $\#$, severe.

The data for height of epithelium and BrdU indices are given as mean \pm SD values.

Histopathological findings and BrdU labeling index data for the urinary bladder epithelium are summarized in Table 2. Simple hyperplasia, papillary or nodular (PN) hyperplasia, a putative preneoplastic lesion ${ }^{14}$, and squamous metaplasia were seen in BBN-treated rats but not in control animals. The animals given BBN showed marked increases in height and BrdU labeling indices of the urinary bladder epithelium (Fig. 1). In particular, incidences of simple and PN hyperplasia were significantly higher in the BBN-treated group than in control group at the end of week 8.

\section{Discussion}

It is well known that carcinogen or promoting chemical insult induces a rapid increase in cell division in the urinary bladder epithelium, resulting in epithelial hyperplasia as observed by light microscopy ${ }^{15,16}$. The results of the present investigation provide clear evidence of such a response of the urinary bladder epithelium in NBR rats to BBN.

Concerning rat urinary bladder carcinogenesis, the Fischer 344 rat is the most commonly used strain ${ }^{1-11,14-16}$. In Fischer 344 male rats treated with $0.05 \% \mathrm{BBN}$ in the drinking water for 4 weeks, marked incorporation of $\mathrm{BrdU}$ and severe simple hyperplasia are seen in the urinary bladder epithelium ${ }^{16}$. The urinary bladder changes observed in the present study were estimated to be quantitatively and qualitatively 


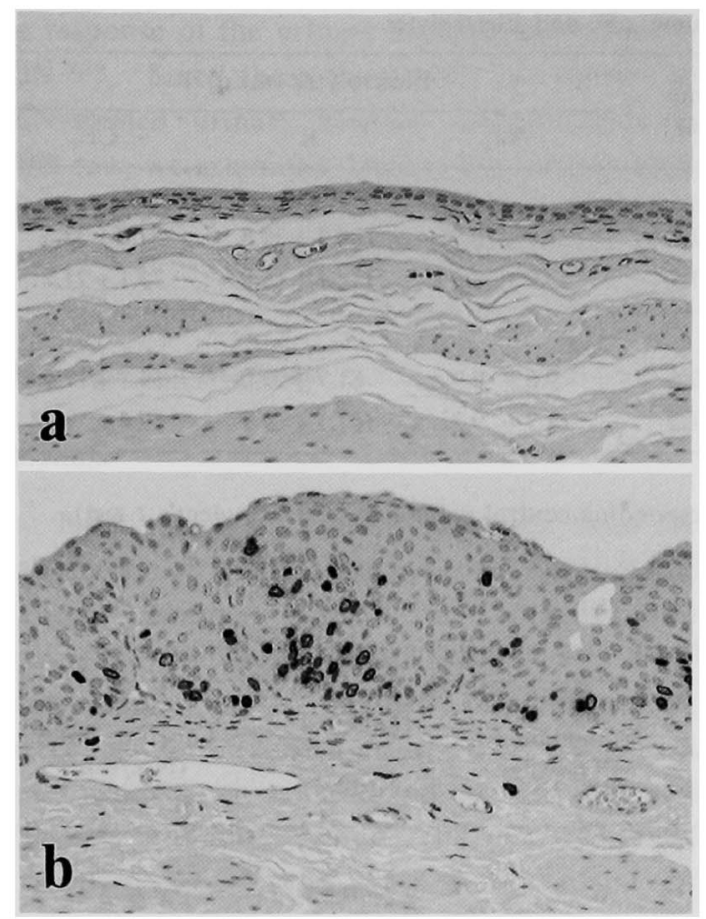

Fig. 1. BrdU immunohistochemical staining of urinary bladder epithelia from rats sacrificed at the end of week $8 . \quad \times 160$.

(a) Control

Lack of BrdU positive cells in normal epithelium.

(b) BBN treatment

A large number of BrdU-incorporating cells are observed in an area of PN hyperplasia.

equally severe as those in the Fischer 344 strain. Therefore, BBN was confirmed to act typically on the NBR rat urinary bladder carcinogenesis indicating that NBR rats treated with this carcinogen can be regarded as initiated for the purpose of investigating the relation of $\alpha \mathbf{2} \mu$-globulin to the promotion stage.

\section{References}

1. Tamano, S, Asakawa, E, Boomyaphiphat, P, Masui, $\mathrm{T}$, and Fukushima, $\mathrm{S}$ : Lack of promotion of $\mathrm{N}$ butyl- $N$-(4-hydroxybuthyl)nitrosamine-intiated urinary bladder carcinogenesis in mice by rat cancer promoters. Teratog Carcinog Mutagen 13 : 89-96, 1993.

2. Nakanishi, K, Hagiwara, A, Shibata, M, Imaida, K, Tatematsu, $M$, and Ito, $N$ : Dose response of saccharin in induction of urinary bladder hyperplasia in Fischer 344 rats pretreated with $N$-butyl- $N$-(4- hydroxybuthyl). J Natl Cancer Inst 65 : 1005-1010, 1980.

3. IARC monographs: IARC monographs on the evaluation of the carcinogenic risk of chemicals to humans. In: Some Non-Nutritive Sweeting Agents, International Agency for Research on Cancer, Lyon, France, 1980.

4. Ellwein, LB, and Cohen, SM: The health risk of saccharin revisited. Crit Rev Toxicol 20 : 311-326, 1990.

5. Cohen, SM, Cano, M, Earl, RA, Carson, SD, and Garland, EM : A proposed role for silicates and protein in the proliferative effects of saccharin on the male urothelium. Carcinogenesis 12: 155!-1555, 1991.

6. Chatterjee, B, Demyan, WF, Song, CS, Garg, BD, and Roy, AK: Loss of androgenic induction of $\alpha 2 \mathrm{u}$-globulin gene family in the liver of NIH black rats. Endocrinology 125 : 1385-1388, 1989.

7. Dietrich, DR and Swenberg, JA : NCI-Black-Reiter (NBR) male rats fail to develop renal disease following exposure to agents that induce $\alpha 2 u$-globulin ( $\alpha 2 u)$ nephropathy. Fundam Appl Toxicol 16: 749-762, 1991.

8. Fukushima, S, Hagiwara, A, Ogiso, T, Shibata, M, and Ito, N : Promoting effects of various chemicals in rat urinary bladder carcinogenesis initiated by $N$ nitroso- $N$-butyl-(4-hydroxybuthyl)amine. Food chem Toxicol 21 : 59-68, 1983.

9. Hagiwara, A, Fukushima, S, Kitaori, M, Shibata, M, and Ito, $\mathrm{N}$ : Effects of three sweeters on rat urinary bladder carcinogenesis initiated by $\mathrm{N}$-butyl- $\mathrm{N}$-(4hydroxybutyl)nitrosamine. Gann 75: 763-768, 1984.

10. Ito, $\mathbf{N}$ and Fukushima, $\mathbf{S}$ : Promotion of urinary bladder carcinogenesis in experimental animals. Exp Pathol 36: 1-15, 1989.

11. Kurata, Y, Asamoto, M, Haigwara, A, Masui, T, and Fukushima, $S$ : Promoting effects of various agents in rat urinary bladder carcinogenesis initiated by $N$ butyl- $N$-(4-hydroxybutyl)nitrosamine. Cancer Lett 32 : 125-135, 1986.

12. Mori, S, Kurata, K, Takeuchi, Y, Toyama, M, Makino, S, and Fukushima, S: Influences of strain and diet on the promoting effects on sodium 2ascorbate in two-stage urinary bladder carcinogenesis in rats. Cancer Res $47: 3492-3495$, 1987.

13. Nakanowatari, J-I, Fukushima, S, Imaida, K, Ito, N, and Nagase, $\mathbf{S}$ : Strain differences in $\mathrm{N}$-butyl- $\mathrm{N}$ (4-cydroxybutyl)nitrosamine bladder carcinogenesis in rats. Jpn J Cancer Res $79:$ 453-459, 1988.

14. Fukushima, S, Murasaki, G, Hirose, M, Nakanishi, $\mathbf{K}$, Hasegawa, $\mathbf{R}$, and Ito, $\mathbf{N}$ : Histopathological analysis of preneoplastic changes during $N$-butyl$\boldsymbol{N}$-(4-hydroxybuthyl)nitrosamine-induced urinary bladder carcinogenesis in rats. Acta Pathol Jpn 32 : 243-250, 1982.

15. Friedell, GH, Jacobs, JB, Nagy, GK, and Cohen, SM: The pathogenesis of bladder cancer. Am J Pathol 89: 432-442, 1977. 
16. Shibata, M-A, Yamada, M, Tanaka, H, Kagawa, M, and Fukushima, $\mathbf{S}$ : Changes in urine composition, bladder epithelial morphology, and DNA synthesis in male F344 rats in response to ingestion of bladder tumor promoters. Toxicol Appl Pharmacol 99 : $37-49,1989$. 